\title{
Number of Endothelial Progenitor Cells in Peripheral Artery Disease as a Marker of Severity and Association with Pentraxin-3, Malondialdehyde-Modified Low-Density Lipoprotein and Membrane Type-1 Matrix Metalloproteinase
}

\author{
Tetsuji Morishita ${ }^{1}$, Hiroyasu Uzui ${ }^{1}$, Akira Nakano ${ }^{1}$, Yasuhiko Mitsuke ${ }^{1}$, Toru Geshi ${ }^{1}$, Takanori Ueda ${ }^{2}$ and \\ Jong-Dae Lee ${ }^{1}$
}

${ }^{1}$ Department of Cardiovascular Medicine, University of Fukui Hospital, Fukui, Japan

${ }^{2}$ First Department of Internal Medicine, University of Fukui Hospital, Fukui, Japan

\begin{abstract}
Aims: Circulating endothelial progenitor cells (EPCs) were mobilized in cardiac ischemia, heart failure and vascular injuries associated with endothelial damage. Despite the occurrence of endothelial dysfunction in peripheral artery disease (PAD), few data are available on EPC mobilization in this setting.

Methods: We investigated the correlations between EPC and disease severity and also other biomarkers in PAD. EPCs assessed as CD34 ${ }^{+}$cells co-expressing CD $45^{\mathrm{dim}}, \mathrm{CD} 133$ and vascular endothelial growth factor receptor- 2 were studied in PAD $(n=48)$ and non-PAD $(n=22)$ patients. Membrane type-1 matrix metalloproteinase (MT1-MMP) on peripheral blood mononuclear cells, serum malondialdehyde-modified low-density lipoprotein (MDA-LDL) and plasma pentraxin-3 were also measured.

Results: The EPC level changed in the Fontaine and Trans-Atlantic Inter-Society Consensus (TASC) II classification. EPC was increased in Fontaine class II a as compared with class IV and non-PAD patients $(p<0.05)$. EPCs and pentraxin-3 were increased in TASC II type A/B as compared with type $\mathrm{C} / \mathrm{D}$ and non-PAD patients $(p<0.05)$, whereas the expression of MT1-MMP on peripheral blood mononuclear cells was significantly decreased in TASC II type A/B (both $p<0.05$ versus type C/D and non-PAD patients). The EPC level showed a positive association with pentraxin-3 $(r=0.31 ; p<$ $0.05)$. There was an inverse association between the EPC level and MT1-MMP $(r=-0.54 ; p<0.01)$. The cardiovascular events was associated with reduced EPC and increased MDA-LDL $(p<0.05)$.

Conclusion: EPC changed according to the Fontaine and TASC II classification and decreased in the advanced phases, and was associated with novel biomarkers and related to the severity of PAD.
\end{abstract}

JAtheroscler Thromb, 2012; 19:149-158.

Key words; Endothelial progenitor cells, Peripheral artery disease,

Membrane type-1 matrix metalloproteinase, Pentraxin-3

\section{Introduction}

Circulating endothelial progenitor cells (EPCs), which have the ability to differentiate into mature en-

Address for correspondence: Hiroyasu Uzui, Department of Cardiovascular Medicine, University of Fukui Hospital, 23-3

Shimoaizuki, Matsuoka, Fukui, 910-1193 Japan

E-mail: huzui@u-fukui.ac.jp

Received: May 17, 2011

Accepted for publication: August 12, 2011 dothelial cells, can home to organs undergoing atherosclerotic endothelial dysfunction, where they induce angiogenesis ${ }^{1)}$, vasculogenesis, and vessel repair ${ }^{2)}$. Circulating EPC levels are altered in cardiac ischemia ${ }^{3)}$, heart failure ${ }^{4)}$, and vascular injuries ${ }^{5,6)}$ caused by endothelial damage.

Inflammation $^{7)}$ and oxidative stress ${ }^{8)}$ are involved in EPC mobilization ${ }^{9}$. Pentraxin-3, which is produced predominantly by macrophages and vascular endothelial cells, is considered to reflect inflammation of the 
endothelium ${ }^{10,11)}$ more directly than levels of C-reactive protein ${ }^{12)}$; however, the relationship between EPCs and pentraxin-3 remains unclear. Malondialdehyde-modified low-density lipoprotein (MDA-LDL) is an oxidized lipoprotein, which is increased in patients with coronary artery disease ${ }^{13)}$ and associated with stent restenosis in patients with diabetes mellitus ${ }^{14)}$. Oxidized low-density lipoprotein decreased the survival of EPCs and impaired their function through decreased endothelial nitric oxide synthetase expres$\operatorname{sion}^{15)}$

EPC mobilization occurs also through matrix metalloproteinase-mediated mechanisms ${ }^{16-18)}$. Matrix metalloproteinase species activate local protease activity and weaken stromal cell-EPC interactions in the bone marrow. Membrane type-1 matrix metalloproteinase (MT1-MMP), which contributes to vascular remodeling and atherosclerotic plaque disruption ${ }^{19)}$, was shown to regulate the mobilization of $\mathrm{CD} 34^{+}$ progenitor cells from the bone marrow in a mouse model ${ }^{17)}$.

In spite of the occurrence of endothelial dysfunction in peripheral artery disease (PAD), little information is available on EPC mobilization in these patients according to clinical status. In this study, we aimed to investigate the patterns of EPC mobilization in patients with PAD and to evaluate the association of EPCs with inflammation and oxidative stress markers.

\section{Methods}

\section{Study Subjects and Design}

Patients were recruited from the Department of Cardiovascular Medicine of the University of Fukui Hospital. Seventy patients were enrolled in this study. Ethics committee approval and informed consent from all patients were obtained. The patients were classified into 2 groups: patients with PAD $(n=48)$ and patients without PAD $(n=22)$, who were used as gender- and age-matched controls. The diagnosis of PAD was assessed by patient complaints (claudication, numbness, and resting pain), physical pulse examination, an ankle-brachial index lower than 0.90 , and duplex sonography. Patients with a history of neoplastic, hepatic, infectious, or autoimmune diseases were excluded from this study. Chronic kidney disease was defined as estimated glomerular filtration rate of less than $60 \mathrm{~mL} / \mathrm{min} /$ $1.73 \mathrm{~m}^{2}$.

All PAD patients received catheter angiography and/or computed tomography angiography. The Fontaine clinical classification and the Trans-Atlantic Inter-Society Consensus (TASC) II classification ${ }^{20)}$ were made on the basis of clinical symptoms and the results of angiography.

Circulating EPC levels, which were assessed as $\mathrm{CD} 34^{+}$cells co-expressing CD $45^{\mathrm{dim}}, \mathrm{CD} 133$ and vascular endothelial growth factor receptor-2, were studied in $70 \mathrm{PAD}$ and non-PAD patients. The expression of MT1-MMP on peripheral blood mononuclear cells, the plasma levels of pentraxin-3, the serum levels of MDA-LDL and the plasma levels of stromal cellderived factor-1 (SDF-1) were measured in 39, 42, 37 and 45 patients, respectively. All patients were treated with ordinary regimens, and all drugs were continued in all patients before blood collection.

We observed the vascular events that occurred during the follow-up period [mean (SD), 8.4 (4.8) months], and examined the possibility of a correlation between the events and EPC levels, MT1-MMP levels, pentraxin-3 levels, MDA-LDL levels and SDF-1 levels. During the follow-up period, vascular events defined as cardiovascular death (including sudden deaths and deaths from myocardial infarction or heart failure), cardiovascular revascularization (percutaneous coronary and peripheral intervention or bypass surgery), stent thrombosis, stent restenosis, non-healing ulcers, and amputation were counted.

\section{Pentraxin-3, MDA-LDL and SDF-1 Measurements}

Pentraxin-3, MDA-LDL and SDF-1 levels were measured by commercially available sandwich ELISA for pentraxin-3 (Perseus Proteomics Inc., Tokyo, Japan) MDA-LDL (Sekisui Medical Co., Inc., Tokyo, Japan) and SDF-1 (R\&D Systems Inc., Minneapolis, $\mathrm{MN}$ ), respectively.

\section{Flow Cytometry Analysis}

EPCs and MT1-MMP levels were quantified in collected blood samples by flow cytometry. EPCs were analyzed for the expression of CD34, CD45, CD133, vascular endothelial growth factor receptor-2 with four-color flow cytometry (FACSCalibur; BD Biosciences, Franklin Lakes, NJ, USA). Two milliliters of whole blood was obtained. Red cells were lysed by the addition of ammonium chloride-based lysing reagent. The samples were washed in $0.2 \%$ phosphate-buffered saline with bovine serum albumin. FcR-blocking reagent (1\% human gamma-globulin; Sigma-Aldrich Inc., St. Louis, MO, USA) was added and incubated for 15 minutes at room temperature in the dark. The samples were incubated with anti-CD34 FITC (Beckman Coulter Inc., Marseille, France), anti-CD45-PerCP (BD Biosciences), anti-CD133/2 (293C3)-APC (Miltenyi Biotec $\mathrm{GmbH}$, Bergisch Gladbach, Germany), and anti- vascular endothelial growth factor receptor-2-phycoerythrin Conjugated (R\&D Systems) 
A

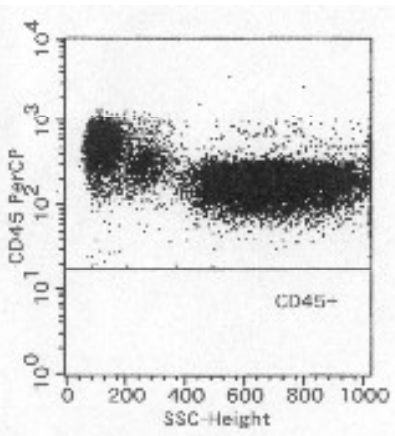

B

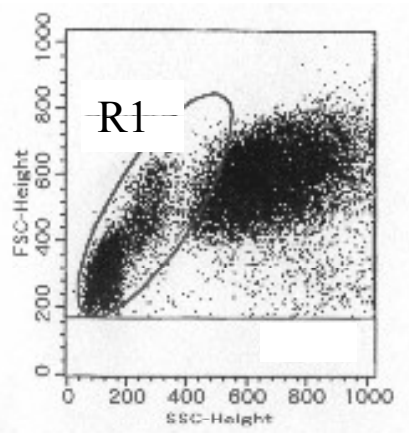

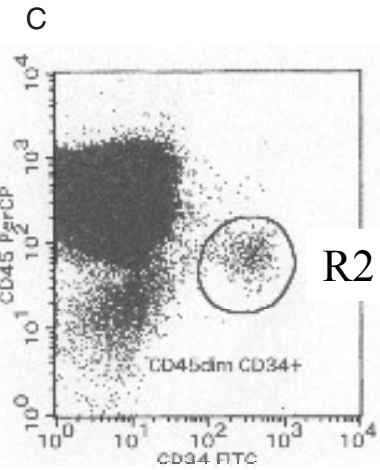

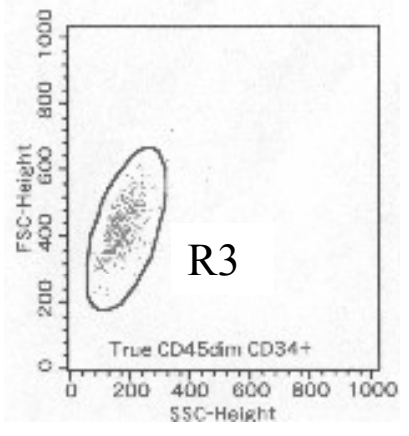

$\mathrm{D}$

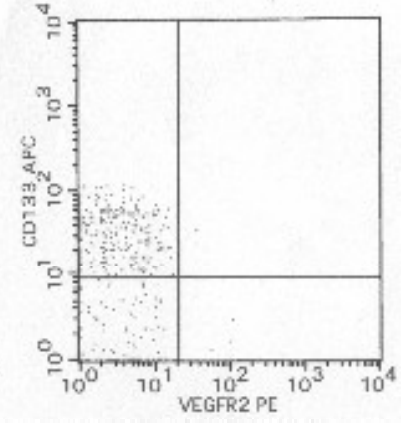

E

Fig. 1. Flow cytometry quantification of EPC following the multi-gating strategy (see Methods section)

(A) CD45 versus side scatter dot plot included all $\mathrm{CD} 45^{+}$events. (B) $\mathrm{CD} 45^{+}$cells were gated on a forward scatter versus side scatter dot plot to confirm mononuclear cell fraction (R1). (C) $\mathrm{CD} 34^{+}$and CD $45^{\mathrm{dim}}$ cells in the mononuclear cell fraction (R2). (D) A cluster of true CD $45^{\mathrm{dim}} \mathrm{CD} 34^{+}$cells was gated on a forward scatter versus side scatter dot plot (R3). (E) CD $45^{\mathrm{dim}} \mathrm{CD} 34^{+} \mathrm{CD} 133^{+}$vascular endothelial growth factor receptor- $2^{+}$cells were enumerated in upper right quadrant of plot.

for 40 minutes at $4{ }^{\circ} \mathrm{C}$, followed by erythrolysis by the addition of lysing reagent, and were washed once with $0.2 \%$ phosphate-buffered saline with bovine serum albumin. The cells were resuspended in $0.2 \%$ phosphate-buffered saline with bovine serum albumin for flowcytometric analysis. As a control for analysis, cells in a separate tube were treated with PE-labeled mouse IgG1 antibody. CD $34^{+}$cells were analyzed using sequential gating strategies. CD45 versus side scatter dot plot was set to include all CD $45^{+}$events (Fig. 1A). $\mathrm{CD} 45^{+}$events were established to include all nucleated white blood cells and to exclude red blood cells, nucleated red blood cells, platelets, and other cellular debris, which do not express CD $45 . \mathrm{CD} 45^{+}$cells were gated on a forward scatter versus side scatter dot plot to confirm mononuclear cell fraction (Fig. 1B, R1). Mononuclear cells formed a cluster with low side scatter and low to intermediate forward scatter. We gated $\mathrm{CD} 34^{+}$and $\mathrm{CD} 45^{\mathrm{dim}}$ cells in the mononuclear cell fraction (Fig. 1C, R2) and gated on a forward scatter versus side scatter dot plot to obtain a cluster of true

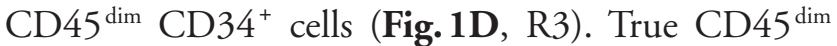
and $\mathrm{CD} 34^{+}$events were displayed on a CD133 versus vascular endothelial growth factor receptor-2 dot plot and then the resulting population was examined for the dual expression of vascular endothelial growth factor receptor-2 and CD133. CD $45^{\mathrm{dim}} \mathrm{CD} 34^{+} \mathrm{CD} 133^{+}$ vascular endothelial growth factor receptor- $2^{+}$cells were enumerated in the upper right quadrant of plot (Fig. 1E). At least 2,000,000 events were measured in the $\mathrm{CD} 45^{+}$gate. The same trained operator, who was blind to the patient's clinical status, performed the entire test throughout the study. Data were analyzed using CELLQuest (BD Biosciences).

The EPC values were defined as the percentage of $\mathrm{CD} 34^{+}, \mathrm{CD} 45^{\mathrm{dim}}, \mathrm{CD} 133^{+}$, and vascular endothelial growth factor receptor- $2^{+}$cells per $\mathrm{CD} 34^{+} \mathrm{CD} 45^{\mathrm{dim}}$ cells fraction. The surface expression of MT1-MMP was estimated by the frequency of CD14-positive cells expressing MT1-MMP at the single cell level, as described previously ${ }^{21)}$. 
Table 1. Patient Characteristics

\begin{tabular}{|c|c|c|c|}
\hline Characteristics & PAD & non-PAD & $P$ Value \\
\hline No. & 48 & 22 & \\
\hline Age [mean $(\mathrm{SD})$ years $]$ & $74.6(8.1)$ & $70.5(9.8)$ & 0.071 \\
\hline Gender (n, male/female) & $37 / 11$ & $18 / 4$ & 0.761 \\
\hline CAD, n (\%) & $28(58.3)$ & $13(59.1)$ & $>0.999$ \\
\hline Stroke, n (\%) & $16(33.3)$ & $1(4.5)$ & 0.014 \\
\hline Hypertension, n (\%) & $46(95.8)$ & $15(68.2)$ & 0.003 \\
\hline $\mathrm{DM}, \mathrm{n}(\%)$ & $30(62.5)$ & $9(40.9)$ & 0.122 \\
\hline Dyslipidemia, n (\%) & $28(58.3)$ & $14(63.6)$ & 0.442 \\
\hline Smoking, n (\%) & $34(70.8)$ & $15(68.2)$ & $>0.999$ \\
\hline CKD, n (\%) & $27(56.3)$ & $9(40.9)$ & 0.305 \\
\hline \multicolumn{4}{|l|}{ TASC II, n (\%) } \\
\hline A & $2(4.2)$ & N.A. & N.A. \\
\hline $\mathrm{B}$ & $6(12.5)$ & N.A. & N.A. \\
\hline $\mathrm{C}$ & $5(10.4)$ & N.A. & N.A. \\
\hline $\mathrm{D}$ & $35(72.9)$ & N.A. & N.A. \\
\hline \multicolumn{4}{|l|}{ Fontaine, n (\%) } \\
\hline I & $4(8.3)$ & N.A. & N.A. \\
\hline Па & $10(20.8)$ & N.A. & N.A. \\
\hline II b & $16(33.3)$ & N.A. & N.A. \\
\hline III & $10(20.8)$ & N.A. & N.A. \\
\hline IV & $8(16.7)$ & N.A. & N.A. \\
\hline
\end{tabular}

PAD: peripheral artery disease, CAD: coronary artery disease, DM: diabetes mellitus, CKD: Chronic kidney disease, TASC: Trans-Atlantic Inter-Society Consensus, N.A.: not available.

\section{Statistical Analysis}

Data are expressed as the mean (SD). Fisher's exact test was used to compare the categorical data. Comparisons between 2 or more groups of continuous measurements were performed by an unpaired Student's $t$ test or ANOVA followed by multiple comparison tests using Fisher's PLSD test for 3 groups and Scheffe's test for more than 4 groups, respectively. Correlations between 2 variables were assessed by Pearson's coefficient (r). Statistical significance was accepted at $p<0.05$.

\section{Results}

\section{Patient Characteristics}

The clinical characteristics of the patients are summarized in Table 1. There was a high frequency of coronary artery stenosis, stroke, and other cardiovascular risk factors in both groups. The patient backgrounds were matched between the PAD and nonPAD patient groups, except for the prevalence of hypertension and stroke. The TASC II and Fontaine classification results are also shown in the table.

The study subjects were divided into 4 groups $(\mathrm{PAD}+$ coronary artery disease $(\mathrm{CAD}), \mathrm{PAD}$ alone,
$\mathrm{CAD}$ alone and non-vascular patients) to compare the EPC levels among groups. EPC levels in PAD + CAD patients $\left[1.3(1.3) \% / C D 34{ }^{+} \mathrm{CD} 45^{\mathrm{dim}}\right.$ cells] were higher than those in non-vascular patients $[0.4(0.5)$ $\% / \mathrm{CD} 34^{+} \mathrm{CD} 45^{\mathrm{dim}}$ cells, $\left.p=0.035\right]$ and CAD-alone patients [0.6 (0.6) \%/CD34 ${ }^{+} \mathrm{CD} 45^{\mathrm{dim}}$ cells, $\left.p=0.035\right]$. No significant difference was found between the EPC levels in PAD + CAD patients and those in PAD patients [1.1 (1.2) \%/CD34 ${ }^{+} \mathrm{CD} 45^{\mathrm{dim}}$ cells, $\left.p=0.381\right]$. We screened the prevalence of CAD in each Fontaine I/II and III/IV group. The prevalence of CAD showed no significant difference between the Fontaine I/II group $[20 / 30(66.7 \%)]$ and Fontaine III/IV group [8/18 (44.4\%), $p=0.147]$.

\section{Circulating EPCs in Patients with PAD}

The distribution of EPCs according to the Fontaine classification is delineated in Fig. 2A. EPC levels in Fontaine class $\Pi$ a patients [2.2 (1.6)\%/CD34 ${ }^{+}$ CD $45^{\mathrm{dim}}$ cells] were higher than those in class IV [0.5 $(0.4) \% / \mathrm{CD} 34^{+} \mathrm{CD} 45^{\mathrm{dim}}$ cells, $\left.p=0.041\right]$ and nonPAD patients $\left[0.6(0.6) \% / \mathrm{CD} 34^{+} \mathrm{CD} 45^{\mathrm{dim}}\right.$ cells, $p=$ $0.0061]$. Additionally, EPC levels in class IV were nonsignificantly decreased compared with those in nonPAD patients. 


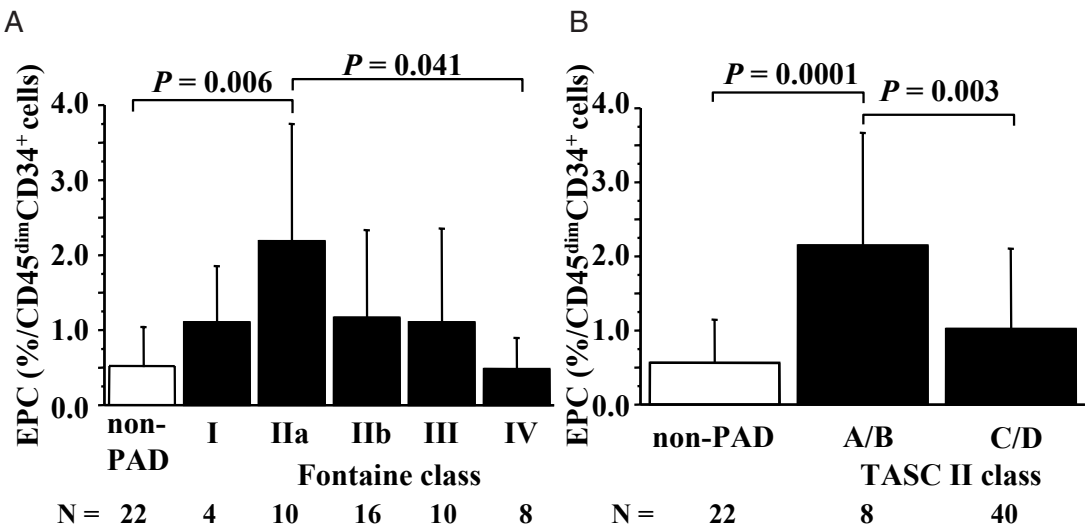

Fig. 2.

(A) Bar graphs illustrating endothelial progenitor cell (EPC) levels in peripheral arterial disease (PAD) and non-PAD patients classified according to the Fontaine classification. EPC levels in Fontaine class II a patients were significantly higher than in class IV and non-PAD patients. (B) Bar graphs illustrating EPC levels in PAD and non-PAD patients classified according to the Trans-Atlantic Inter-Society Consensus (TASC) II classification. EPC in TASC II type A/B patients were significantly higher than in type $\mathrm{C} / \mathrm{D}$ and non-PAD patients.

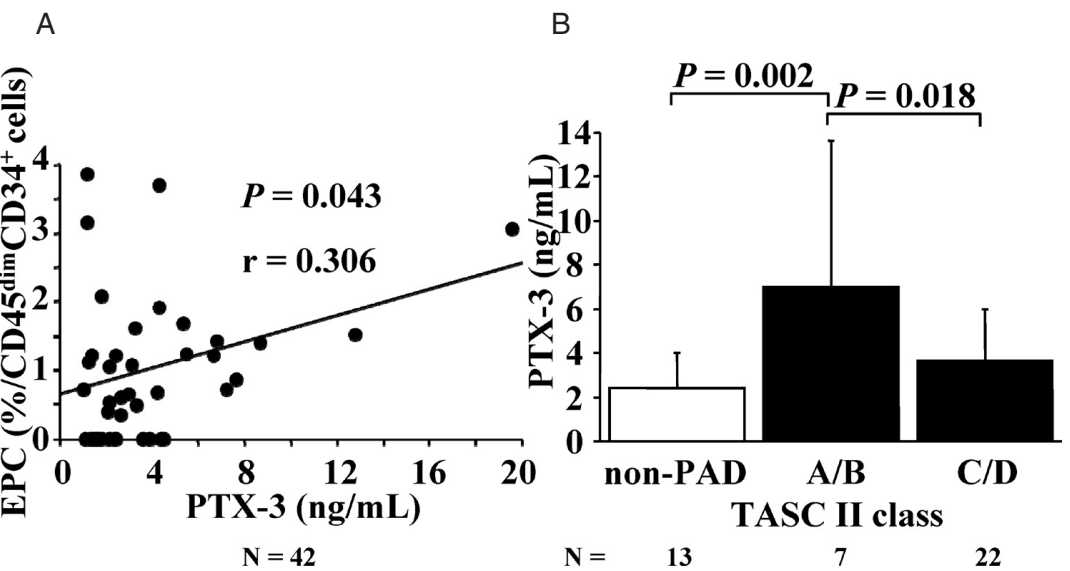

Fig.3.

(A) Correlation between EPC and pentraxin-3 (PTX-3) levels. EPCs were positively correlated with pentraxin-3. (B) Pentraxin-3 levels in PAD and non-PAD patients classified according to TASC II classification. Pentraxin-3 in TASC II type A/B cases was higher than in type $\mathrm{C} / \mathrm{D}$ and non-PAD.

Fig. 2B presents the correlation between EPC levels and the TASC II classification. EPC levels in TASC II type A/B patients [2.1 (1.5)\%/CD $34^{+} \mathrm{CD} 45^{\mathrm{dim}}$ cells] were higher than in type C/D $\left[1.0(1.1) \% / C D 34^{+}\right.$ CD $45^{\mathrm{dim}}$ cells, $p=0.003$ and non-PAD patients $[0.6$ $(0.7) \% / \mathrm{CD} 34^{+} \mathrm{CD} 45^{\mathrm{dim}}$ cells, $\left.p=0.0001\right]$.

\section{Relationship between pentraxin-3 and EPCs; Pentraxin-3 in TASC II Classification}

The correlation between EPC and pentraxin-3 levels is presented in Fig. 3A. EPC levels showed a significantly positive association with pentraxin-3 $(r=$
$0.31 ; p=0.043)$. The plasma pentraxin-3 levels in patients in each TASC II stage are shown in Fig. 3B. Pentraxin-3 in TASC II type A/B cases [7.0 (6.6) ng/ $\mathrm{mL}]$ was significantly higher than in type C/D [3.7 (2.3) ng/mL, $p=0.018]$ and non-PAD patients [2.7 (1.6) $\mathrm{ng} / \mathrm{mL}, p=0.002]$.

\section{Relationship between MT1-MMP and EPCs; MT1-MMP in TASC II Classification}

We observed an inverse association between EPC and MT1-MMP levels $(r=-0.54 ; p=0.0004)$ (Fig. 4A). MT1-MMP in TASC II type A/B patients [11.2 
A

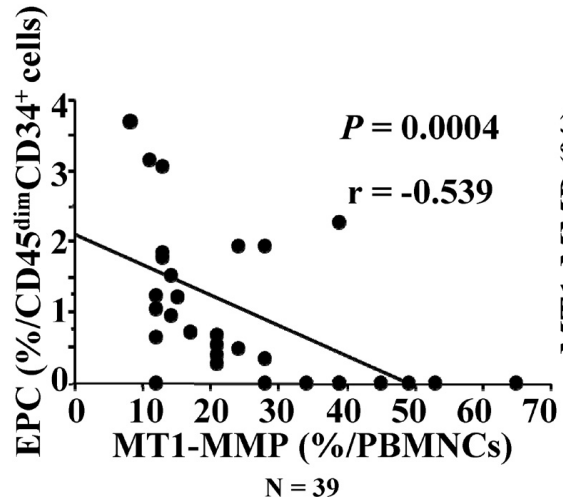

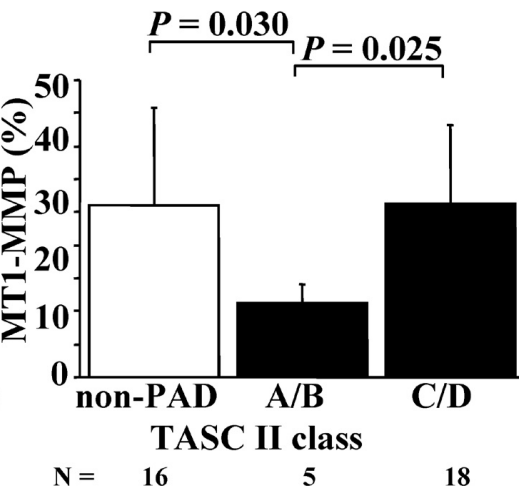

Fig. 4 .

(A) Correlation between EPC and MT1-MMP levels. EPCs were negatively correlated with MT1-MMP levels. (B) MT1-MMP levels in PAD and non-PAD patients classified according to TASC II classification. MT1-MMP in TASC II type A/B patients was lower than in type $\mathrm{C} / \mathrm{D}$ and non-PAD patients.

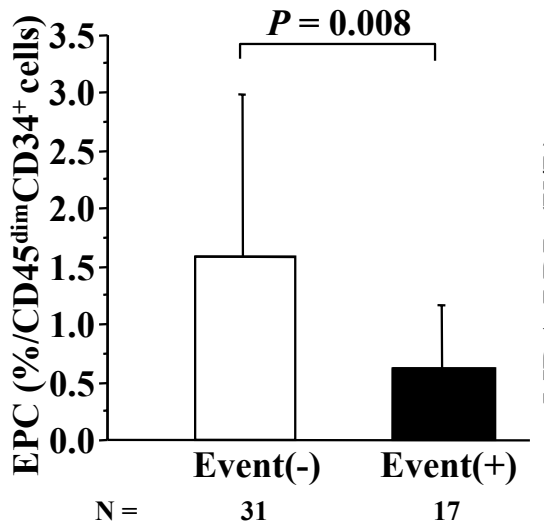

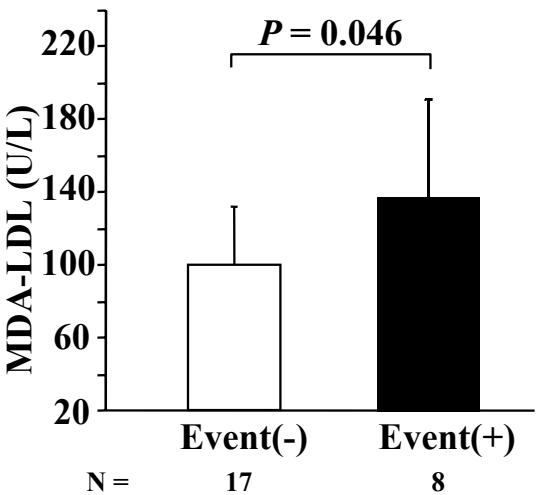

Fig. 5. EPC and MDA-LDL levels in patients with cardiovascular events and without events in the PAD patient group

(A) EPC numbers in patients with events were lower than in patients without events. (B) MDA-LDL in patients with events was higher than in patients without events.

(2.9)\%] was lower than in type C/D [26.2 (11.9)\%, $p=0.025]$ and non-PAD patients [28.0 (20.3)\%, $p=0.030]$, as illustrated in Fig. 4B.

\section{MDA-LDL and EPCs in Patients with Cardiovascular} Events

During the follow-up period, 20 patients developed 21 cardiovascular events (amputation, 3; nonhealing ulcer, 1 ; bypass surgery, 3 ; percutaneous peripheral intervention, 11; and percutaneous coronary intervention, 3). Fig. 5A shows the association between EPC levels and the occurrence of vascular events. EPC in patients with vascular events [0.6 (0.6)
$\% / C D 34^{+} \mathrm{CD} 45^{\mathrm{dim}}$ cells] were significantly lower than in those without vascular events [1.6 (1.4) \%/CD34 ${ }^{+}$ CD45 $5^{\mathrm{dim}}$ cells, $\left.p=0.008\right]$.

The prevalence of vascular events was higher in Fontaine III/IV patients [12/18 (66.7\%)] than in Fontaine I/II patients [5/30 (16.7\%), $p=0.001]$. The study subjects were divided into 2 groups (Fontaine I /II and III/IV) to compare EPC levels between patients with and without events. As a result, in both groups, EPC were nonsignificantly lower in patients with than without events [Fontaine I/II; 0.9 (0.9) vs. 1.6 (1.3) \%/ $\mathrm{CD} 34^{+} \mathrm{CD} 45^{\mathrm{dim}}$ cells, $p=0.267$, Fontaine III/IV; 0.5 (0.4) vs. $1.5(1.5) \% / \mathrm{CD} 34^{+} \mathrm{CD} 45^{\mathrm{dim}}$ cells, $\left.p=0.051\right]$. 
MDA-LDL distribution did not change according to the Fontaine and TASC II classifications, whereas MDA-LDL in patients with vascular events [128.9 (60.2) U/L] was significantly increased compared to those without vascular events $[88.8$ (35.2) U/L, $p=$ 0.046] (Fig. 5B). We could not identify any association between MDA-LDL values and the levels of other biomarkers, EPC $(r=-0.18 ; p=0.30)$, pentraxin-3 $(r=-0.19 ; p=0.26)$, or MT1-MMP levels $(r=-0.04$; $p=0.87)$.

SDF-1 in PAD cases [2862.7 (739.2) pg/mL] was significantly higher than in non-PAD cases [2192.0 (554.3) $\mathrm{pg} / \mathrm{mL}, p=0.028]$; however, we could not find any association between SDF-1 and the levels of other biomarkers, EPC $(r=0.15 ; p=0.34)$, pentraxin-3 $(r=0.16 ; p=0.37)$, MT1-MMP $(r=0.15 ; p=$ $0.47)$ and MDA-LDL $(r=0.06 ; p=0.75)$. pentraxin-3, MT1-MMP and SDF-1 levels in patients with vascular events were not significantly different from those without [pentraxin-3; 4.1 (3.9) vs. $3.4(1.8) \mathrm{ng} /$ $\mathrm{mL}, p=0.56$, MT-1MMP; 25.5 (17.2) \% vs. 22.1 (8.4) $\%, p=0.54$, SDF-1; 2831.5 (756.9) vs. 2612.0 (737.9) $\mathrm{pg} / \mathrm{mL}, p=0.36$, respectively].

\section{Discussion}

On the basis of our data, we reached the following conclusions. EPC levels were inversely related to Fontaine and TASC II classifications. EPC levels showed a significant association with the levels of pentraxin-3 and MT1-MMP. In addition, patients with vascular events had significantly lower EPCs and higher MDALDL.

EPC decreased as the disease progressed and, in Fontaine class IV patients, were even lower than in controls. These findings are in accordance with known EPC changes in heart failure ${ }^{4)}$ and diabetes mellitus ${ }^{5)}$. Thus, the number of EPCs indicates the status of a patient on the continuum between EPC exhaustion and endothelial damage. Worsening of cardiovascular disorders and increases in cardiovascular risks cause endothelial dysfunction and decreasing numbers of EPCs. EPCs are closely related to endothelial functions, such as flow-mediated dilatation ${ }^{22)}$ and asymmetric dimethylarginine ${ }^{23}$. EPCs are upregulated and mobilized sufficiently in response to vascular damage in the mild to moderate phase, and in the early stages of endothelial dysfunction, EPCs are sufficiently mobilized and supplied from bone marrow to the damaged organ. As endothelial damage progresses, EPCs are exhausted and cannot respond to and restore endothelial dysfunction.

We also evaluated the potential associations be- tween EPCs and inflammation and oxidative stress. The inflammatory and most studied biomarker, C-reactive protein, is already known to correlate with EPC levels ${ }^{24)}$, but C-reactive protein is also upregulated in non-vascular inflammation. Pentraxin-3, one of the superfamily of pentraxins, which includes C-reactive protein, is highly produced in vascular endothelial and smooth muscle cells in response to atherosclerotic change ${ }^{25)}$; therefore, pentraxin-3 is considered to be a more specific biomarker of vascular inflammation. Our study implies that endothelial damage and vascular inflammation are closely associated with the number of peripheral EPCs in clinical settings.

Although both EPC and pentraxin-3 have been described as markers for cardiovascular events, they also have atheroprotective functions ${ }^{2,26)}$. EPC is already known to promote vascular repair and vasculogenesis, and recent observations support the possibility that pentraxin-3 also possesses atheroprotective ${ }^{26)}$ and cardioprotective effects ${ }^{27}$, in contrast to other pentraxins, such as C-reactive protein and serum amyloid P. Therefore, increased EPC and pentraxin-3 could possibly play a atheroprotective role, thus correlating with the severity of PAD; however, our study only found that EPC and pentraxin-3 were upregulated in TASC A/B patients, and further studies might be required to reveal the detailed atheroprotective role in PAD, including the various other factors affecting PAD $^{28,29)}$

Both SDF-1 and vascular endothelial growth factor attract progenitor cells and are involved in homing, migration and mobilization from bone marrow to peripheral circulation ${ }^{30,31)}$, contributing to vascular regeneration. SDF-1 was upregulated in the PAD group compared with the non-PAD group; however, no significant difference was found between TASC A/B and $\mathrm{C} / \mathrm{D}$ groups in SDF-1 levels. These results may reflect that EPCs are upregulated and mobilized sufficiently in the mild to moderate phase in response to chemokine attraction, such as SDF-1. As disease progresses, EPCs are exhausted or no longer respond to homing signals.

As a surrogate marker of oxidative stress affecting EPC mobilization, we measured MDA-LDL; however, we could not find a relationship between MDALDL and disease severity. MDA-LDL is related to intima-media thickness, but in other settings, including coronary arterial disease and heart failure, a relationship between disease severity and MDA-LDL levels was not found. Additionally, MDA-LDL showed no relationship with the EPC number, but oxidative stress does correlate with EPCs. This mismatch is presumed to be due to the character of MDA-LDL. In 
previous reports ${ }^{32)}$, MDA-LDL was higher in patients with acute coronary syndrome. In contrast, MDALDL in patients with stable angina was similar to control subjects; therefore, we speculate that MDA-LDL levels reflect the existence of unstable plaques, but not disease severity.

Matrix metalloproteinase (MMP) plays a key role in EPC mobilization and angiogenesis ${ }^{16)}$. MT1-MMP, a transmembrane type protease, has been recognized as an important regulator in EPC mobilization from bone marrow and angiogenesis ${ }^{17}$. MT1-MMP cleaves CD44, a cell adhesion molecule, and reduces bone marrow stromal cells and progenitor cell interaction. Our data showed that MT1-MMP expression was high in conditions of decreased and exhausted numbers of EPCs being mobilized from the bone marrow. In conditions where sufficient EPCs were preserved in the peripheral blood pool, MT1-MMP expression was downregulated. Experimental findings in mice ${ }^{17)}$ support this finding. MT1-MMP activity occurs not only in bone marrow, but is also involved in pericellular proteolysis at the site of angiogenesis ${ }^{18)}$. Thus, MT1MMP activity may reflect activation in both bone marrow and areas of angiogenesis, which leads to the mobilization and recruitment of EPCs.

Clinical trials using concepts of vasculogenesis and angiogenesis by EPCs are already being applied for cardiac ischemia, critical limb ischemia, and vasculopathy. The benefit and safety of autologous cell transplant therapy has already been reported ${ }^{33-35)}$, but the mechanisms that will ameliorate a patient's condition are still unclear. Our study contributes to elucidation of the mechanism regulating EPC mobilization and homing.

The limitations of our study must be considered. The present study consisted of observational research in patients with known classical risk factors, and hence, it did not establish a cause-effect relationship of interventional therapy and did not examine subjects without any cardiovascular risk. EPC numbers change in various clinical settings, and EPCs and endothelial function are also impaired. We did not evaluate EPC function or clinical endothelial functions, such as adhesion, proliferation and migratory ability, and flow-mediated dilatation. In other studies ${ }^{4,5,22,36)}$, EPC function and endothelial function were also impaired in patients with cardiovascular disease, and these functions exhibited changes in a similar pattern with respect to EPC number ${ }^{37}$. We assume that EPC and endothelial functions were also impaired in our patient study groups.

Collectively, the results of our studies suggest that EPC mobilization occurs in PAD and shows a bi- phasic response, with elevated EPC in the moderate phase and reduced EPC in the advanced phase. EPC levels are associated with the levels of novel circulating biomarkers and several aspects of PAD, including the severity, progression, and outcome of this disease.

\section{Acknowledgments}

This work was partially supported by a Research Grant from the University of Fukui.

\section{Conflicts of Interest}

none declared.

\section{References}

1) Asahara T, Murohara T, Sullivan A, Silver M, van der Zee R, Li T, Witzenbichler B, Schatteman G, Isner JM: Isolation of putative progenitor endothelial cells for angiogenesis. Science, 1997; 275: 964-967

2) Schmidt-Lucke C, Rössig L, Fichtlscherer S, Vasa M, Britten M, Kämper U, Dimmeler S, Zeiher AM: Reduced number of circulating endothelial progenitor cells predicts future cardiovascular events: proof of concept for the clinical importance of endogenous vascular repair. Circulation, 2005; 111: 2981-2987

3) Werner N, Kosiol S, Schiegl T, Ahlers P, Walenta K, Link A, Böhm M, Nickenig G: Circulating endothelial progenitor cells and cardiovascular outcomes. N Engl J Med, 2005; 353: 999-1007

4) Valgimigli M, Rigolin GM, Fucili A, Porta MD, Soukhomovskaia O, Malagutti P, Bugli AM, Bragotti LZ, Francolini G, Mauro E, Castoldi G, Ferrari R: CD34 + and endothelial progenitor cells in patients with various degrees of congestive heart failure. Circulation, 2004; 110: 12091212

5) Fadini GP, Sartore S, Albiero M, Baesso I, Murphy E, Menegolo M, Grego F, Vigili de Kreutzenberg S, Tiengo A, Agostini C, Avogaro A: Number and function of endothelial progenitor cells as a marker of severity for diabetic vasculopathy. Arterioscler Thromb Vasc Biol, 2006; 26: 2140 2146

6) Yue WS, Wang M, Yan GH, Yiu KH, Yin L, Lee SW, Siu $\mathrm{CW}$, Tse HF: Smoking is associated with depletion of circulating endothelial progenitor cells and elevated pulmonary artery systolic pressure in patients with coronary artery disease. Am J Cardiol, 2010; 106: 1248-1254

7) George J, Goldstein E, Abashidze S, Deutsch V, Shmilovich H, Finkelstein A, Herz I, Miller H, Keren G: Circulating endothelial progenitor cells in patients with unstable angina: association with systemic inflammation. Eur Heart J, 2004; 25: 1003-1008

8) Matsumura M, Fukuda $N$, Kobayashi N, Umezawa $H$, Takasaka A, Matsumoto T, Yao EH, Ueno T, Negishi N: Effects of atorvastatin on angiogenesis in hindlimb ischemia and endothelial progenitor cell formation in rats. J Atheroscler Thromb, 2009; 16: 319-326 
9) Tousoulis D, Andreou I, Antoniades C, Tentolouris C, Stefanadis C: Role of inflammation and oxidative stress in endothelial progenitor cell function and mobilization: therapeutic implications for cardiovascular diseases. Atherosclerosis, 2008; 201: 236-247

10) Miyaki A, Maeda S, Yoshizawa M, Misono M, Sasai H, Shimojo N, Tanaka K, Ajisaka R: Is pentraxin 3 involved in obesity-induced decrease in arterial distensibility? J Atheroscler Thromb, 2010; 17: 278-284.

11) Ohbayashi H, Miyazawa C, Miyamoto K, Sagara M, Yamashita T, Onda R: Pitavastatin improves plasma pentraxin 3 and arterial stiffness in atherosclerotic patients with hypercholesterolemia. J Atheroscler Thromb, 2009; 16: 490-500.

12) Inoue K, Sugiyama A, Reid PC, Ito Y, Miyauchi K, Mukai S, Sagara M, Miyamoto K, Satoh H, Kohno I, Kurata T, Ota H, Mantovani A, Hamakubo T, Daida H, Kodama T: Establishment of a high sensitivity plasma assay for human pentraxin3 as a marker for unstable angina pectoris. Arterioscler Thromb Vasc Biol, 2007; 27: 161-167

13) Tanaga K, Bujo H, Inoue M, Mikami K, Kotani K, Takahashi K, Kanno T, Saito Y: Increased circulating malondialdehyde-modified LDL levels in patients with coronary artery diseases and their association with peak sizes of LDL particles. Arterioscler Thromb Vasc Biol, 2002; 22: 662-666

14) Shigematsu S, Takahashi N, Hara M, Yoshimatsu H, Saikawa T: Increased incidence of coronary in-stent restenosis in type 2 diabetic patients is related to elevated serum malondialdehyde-modified low-density lipoprotein. Circ J, 2007; 71: 1697-1702

15) Ma FX, Zhou B, Chen Z, Ren Q, Lu SH, Sawamura T, Han ZC: Oxidized low density lipoprotein impairs endothelial progenitor cells by regulation of endothelial nitric oxide synthase. J Lipid Res, 2006; 47: 1227-1237

16) Huang PH, Chen YH, Wang CH, Chen JS, Tsai HY, Lin FY, Lo WY, Wu TC, Sata M, Chen JW, Lin SJ: Matrix metalloproteinase- 9 is essential for ischemia-induced neovascularization by modulating bone marrow-derived endothelial progenitor cells. Arterioscler Thromb Vasc Biol, 2009; 29: 1179-1184

17) Vagima Y, Avigdor A, Goichberg P, Shivtiel S, Tesio M, Kalinkovich A, Golan K, Dar A, Kollet O, Petit I, Perl O, Rosenthal E, Resnick I, Hardan I, Gellman YN, Naor D, Nagler A, Lapidot T: MT1-MMP and RECK are involved in human CD34 + progenitor cell retention, egress, and mobilization. J Clin Invest, 2009; 119: 492-503

18) van Hinsbergh VW, Koolwijk P: Endothelial sprouting and angiogenesis: matrix metalloproteinases in the lead. Cardiovasc Res, 2008; 78: 203-212

19) Rajavashisth TB, Xu XP, Jovinge $S$, Meisel $S, X u$ XO, Chai NN, Fishbein MC, Kaul S, Cercek B, Sharifi B, Shah PK: Membrane type 1 matrix metalloproteinase expression in human atherosclerotic plaques: evidence for activation by proinflammatory mediators. Circulation, 1999; 99: 3103-3109

20) Norgren L, Hiatt WR, Dormandy JA, Nehler MR, Harris KA, Fowkes FG, Bell K, Caporusso J, Durand-Zaleski I, Komori K, Lammer J, Liapis C, Novo S, Razavi M, Robbs J, Schaper N, Shigematsu H, Sapoval M, White C,
White J, Clement D, Creager M, Jaff M, Mohler E., Rutherford RB, Sheehan P, Sillesen H, Rosenfield K, Group, T. I. W.: Inter-Society Consensus for the Management of Peripheral Arterial Disease (TASC II). Eur J Vasc Endovasc Surg, 2007; 33 Suppl 1: S1-S75

21) Uzui H, Nakano A, Mitsuke Y, Geshi T, Sakata J, Sarazawa K, Morishita T, Satou T, Ishida K, Lee JD: Acarbose treatments improve arterial stiffness in patients with type 2 diabetes mellitus. Journal of Diabetes Investigation, 2011; 2: $148-153$

22) Steiner S, Niessner A, Ziegler S, Richter B, Seidinger D, Pleiner J, Penka M, Wolzt M, Huber K, Wojta J, Minar E, Kopp CW: Endurance training increases the number of endothelial progenitor cells in patients with cardiovascular risk and coronary artery disease. Atherosclerosis, 2005; 181: 305-310

23) Thum T, Tsikas D, Stein S, Schultheiss M, Eigenthaler M, Anker SD, Poole-Wilson PA, Ertl G, Bauersachs J: Suppression of endothelial progenitor cells in human coronary artery disease by the endogenous nitric oxide synthase inhibitor asymmetric dimethylarginine. J Am Coll Cardiol, 2005; 46: 1693-1701

24) Verma S, Kuliszewski MA, Li SH, Szmitko PE, Zucco L, Wang CH, Badiwala MV, Mickle DA, Weisel RD, Fedak PW, Stewart DJ, Kutryk MJ: C-reactive protein attenuates endothelial progenitor cell survival, differentiation, and function: further evidence of a mechanistic link between C-reactive protein and cardiovascular disease. Circulation, 2004; 109: 2058-2067

25) Introna M, Alles VV, Castellano M, Picardi G, De Gioia L, Bottazzai B, Peri G, Breviario F, Salmona M, De Gregorio L, Dragani TA, Srinivasan N, Blundell T L, Hamilton TA, Mantovani A: Cloning of mouse ptx3, a new member of the pentraxin gene family expressed at extrahepatic sites. Blood, 1996; 87: 1862-1872

26) Norata GD, Marchesi P, Pulakazhi Venu VK, Pasqualini F, Anselmo A, Moalli F, Pizzitola I, Garlanda C, Mantovani A, Catapano AL: Deficiency of the long pentraxin PTX3 promotes vascular inflammation and atherosclerosis. Circulation, 2009; 120: 699-708

27) Salio M, Chimenti S, De Angelis N, Molla F, Maina V, Nebuloni M, Pasqualini F, Latini R, Garlanda C, Mantovani A: Cardioprotective function of the long pentraxin PTX3 in acute myocardial infarction. Circulation, 2008; 117: 1055-1064

28) Morimoto Y, Bando YK, Shigeta T, Monji A, Murohara T: Atorvastatin prevents ischemic limb loss in type 2 diabetes: role of p53. J Atheroscler Thromb, 2011; 18: 200-208

29) Tsai PC, Lin TH, Hsu PC, Wang YS, Liao YC and Juo SH: Polymorphism of $270 \mathrm{~A}>\mathrm{G}$ in BRAP is Associated with Lower Ankle-Brachial Index in a Taiwanese Population. J Atheroscler Thromb, 2011; 18: 413-420

30) Stellos K, Langer H, Daub K, Schoenberger T, Gauss A, Geisler T, Bigalke B, Mueller I, Schumm M, Schaefer I, Seizer P, Kraemer BF, Siegel-Axel D, May AE, Lindemann S, Gawaz M: Platelet-derived stromal cell-derived factor-1 regulates adhesion and promotes differentiation of human CD34 + cells to endothelial progenitor cells. Circulation, 2008; 117: 206-215.

31) Tang JM, Wang JN, Zhang L, Zheng F, Yang JY, Kong X, 
Guo LY, Chen L, Huang YZ, Wan Y, Chen SY: VEGF/ SDF-1 promotes cardiac stem cell mobilization and myocardial repair in the infarcted heart. Cardiovasc Res, 2011; 91: 402-411

32) Holvoet P, Vanhaecke J, Janssens S, Van de Werf F, Collen D: Oxidized LDL and malondialdehyde-modified LDL in patients with acute coronary syndromes and stable coronary artery disease. Circulation, 1998; 98: 1487-1494

33) Matoba S, Tatsumi T, Murohara T, Imaizumi T, Katsuda Y, Ito M, Saito Y, Uemura S, Suzuki H, Fukumoto S, Yamamoto Y, Onodera R, Teramukai S, Fukushima M, Matsubara H, Investigators, T. F.-u. S.: Long-term clinical outcome after intramuscular implantation of bone marrow mononuclear cells (Therapeutic Angiogenesis by Cell Transplantation [TACT] trial) in patients with chronic limb ischemia. Am Heart J, 2008; 156: 1010-1018

34) Subramaniyam V, Waller EK, Murrow JR, Manatunga A, Lonial S, Kasirajan K, Sutcliffe D, Harris W, Taylor WR, Alexander RW, Quyyumi AA: Bone marrow mobilization with granulocyte macrophage colony-stimulating factor improves endothelial dysfunction and exercise capacity in patients with peripheral arterial disease. Am Heart J, 2009; 158: 53-60. e51

35) Quyyumi AA, Waller EK, Murrow J, Esteves F, Galt J, Oshinski J, Lerakis S, Sher S, Vaughan D, Perin E, Willerson J, Kereiakes D, Gersh BJ, Gregory D, Werner A, Moss T, Chan WS, Preti R, Pecora AL: CD34(+) cell infusion after ST elevation myocardial infarction is associated with improved perfusion and is dose dependent. Am Heart J, 2011; 161: 98-105

36) Vasa M, Fichtlscherer S, Aicher A, Adler K, Urbich C, Martin H, Zeiher AM, Dimmeler S: Number and migratory activity of circulating endothelial progenitor cells inversely correlate with risk factors for coronary artery disease. Circ Res, 2001; 89: E1-E7

37) Jialal I, Devaraj S, Singh U, Huet BA: Decreased number and impaired functionality of endothelial progenitor cells in subjects with metabolic syndrome: implications for increased cardiovascular risk. Atherosclerosis, 2010; 211: 297-302 